DOI 10.37882/2500-3682.2021.08.19

\title{
СТРАТЕГИЧЕСКАЯ НЕСТАБИЛЬНОСТЬ КАК ЯВЛЕНИЕ СОВРЕМЕННОСТИ
}

\section{STRATEGIC INSTABILITY AS A PHENOMENON OF MODERNITY}

N. Rotkin

Summary: Theoretical approaches to the concept of «strategic instability" are considered, its substantive characteristics in the modern world are determined. The forms, dimensions, subjects and factors of modern strategic instability are highlighted. Attention is focused on the subjective-technological aspect of modern strategic instability. Substantiated is a significant change in the content of strategic instability under the influence of changes in the nature of modern warfare, the relationship between war and politics, the emergence of wars of a new type, technological effectiveness, controllability, multi-sphere nature and permanence of modern strategic instability.

Keywords: strategic instability, chaos, crisis, war, technologies of destabilization.

\author{
Роткин Николай Викторович \\ Соискатель, Военный университет Министерства \\ обороны Российской Федерации \\ shemodan@bk.ru
}

Аннотация: Рассмотрены теоретические подходы к понятию «стратегическая нестабильность», определены ее содержательные характеристики в современном мире. Выделены формы, измерения, субъекты и факторы современной стратегической нестабильности. Внимание сосредоточено на субъективно-технологическом аспекте современной стратегической нестабильности. Обосновано существенное изменение содержания стратегической нестабильности под влиянием изменений характера современной войны, соотношения войны и политики, появлением войн нового типа, технологичности, управляемости, многосферности и перманентности современной стратегической нестабильности.

Ключевые слова: стратегическая нестабильность, хаос, кризис, война, технологии дестабилизации.
$\Pi$ ожалуй, главная обобщающая характеристика современности заключается в слове «нестабильность». Нестабильность повсюду: в экономике и финансах, политике и социальной сфере, информации и коммуникации, технологиях и экологии, культуре и мировоззрении, войне и мире. Особенно это стало очевидным в прошедшем 2020 году, когда большинству людей на планете пришлось резко поменять отношение к тому, что ранее считалось незыблемым и самим по себе разумеющимся, планомерным и предсказуемым: общение, работу, учебу, досуг, перемещения, здоровье и безопасность.

Всепоглощающая многомерность этого явления вынуждает нас говорить о стратегической нестабильности, влияющей на природу и все стороны общественной жизни. Современная неустойчивость и неопределенность стала наднациональной, внерегиоанальной, многосферной и глобальной, иными словами, вышла на стратегический уровень. При этом классическая синергетическая схема «порядок - хаос - новый порядок» уже не работает, нестабильность приобрела перманентный характер.

Стратегическая нестабильность конечно же не явление исключительно дня сегодняшнего, но в последние десятилетия человечество буквально затягивает в водоворот глобальных кризисов, политических революций, экологических катастроф, новых технологий, экономических и культурных трендов.

Специфической же чертой современной стратегиче- ской нестабильности стала ее технологичность. Акторы глобальной политики освоили технологии управляемой дестабилизации (управляемого хаоса) и нашли им военное применение. Правда управляемой ее назвать трудно, так как работают они в одном направлении - деструктивном. Направленная дестабилизация порождает острейшие политические, социально-экономические и военные кризисы, дестабилизированные страны и регионы погружаются в пучину хаоса на долгие десятилетия, а мировое сообщество как-будто и не интересует рестабилизация кризисных регионов или построение в них какого-либо нового порядка.

Понимание стратегической нестабильности как социального феномена связано с теоретической разработкой проблемы стратегической стабильности, как ее противоположности и декларируемой заветной цели международной политики. Становление научных представлений о стратегической стабильности происходило в 1950 - 60-х годах в конкретных исторических условиях периода «холодной войны». В последующие годы они представляли собой скорее категории международных отношений и международного права, характеризующие состояние отношений между государствами и их коалициями и были связаны с наличием или отсутствием устойчивых отношений между ведущими государствами послевоенного мира и соотношением их стратегического, преимущественно ядерного, вооружения.

Это было связано с тем, что в первую очередь ядер- 
ное оружие понималось как стратегическое, следовательно, в основном его наличие, возможность и угроза применения, соотносились с понятием стратегической стабильности или нестабильности.

Исследователь Н.П. Ромашкина отмечает, что «сегодня речь идет о двух подходах или даже расколе между сторонниками классического отношения к стратегической стабильности, сложившегося в период биполярности (когда собственно и возник сам этот термин) и сторонниками абсолютно нового понимания, вызовов и путей обеспечения стратегической стабильности в современных условиях» [6].

В классическом понимании стратегическая стабильность тождественна собственно военно-стратегической стабильности, которая определяется как «устойчивое состояние отношений между государствами (коалициями государств), при котором ни одна из сторон не намерена первой использовать стратегические силы или стратегические ядерные силы и не реализует программы создания новых стратегических вооружений» [1].

Новое понимание стратегической стабильности связано с изменениями представлений о сущности войны, соотношении войны и политики, о технологичности, управляемости, многосферности и перманентности кризисов. В наше время, когда помимо ядерного и иного оружия на физических принципах, появились иные применимые на стратегическом уровне деструктивные технологии (социогуманитарные, информационные, экономические, политические и т.д.), которые по своему поражающему воздействию сравнимы или даже превосходят традиционное оружие массового поражения, меняется и содержание понятий стратегической стабильности и нестабильности, появляются их новые интерпретации и измерения.

С распадом СССР и двухполярного миропорядка бо́льшую актуальность приобретает именно категория стратегической нестабильности. Исследователи состояния современного мира отмечают его нестабильность. Так, А.С. Панарин еще в 2003 году отмечал, что «XXI век только начался, а уже окрещен в целом как стратегически нестабильный, т.е. как непредсказуемо пертурбационный в самых существенных моментах» [5, С. 5].

Стратегическая нестабильность может быть вызвана нестабильностью определенных социальных систем, регионов, государств, цивилизаций, континентов. В ней можно выделить несколько измерений и сгруппировать по разным основаниям.

С.М. Мандрыка определяет современную стратегическую нестабильность как «состояние, отношение и процесс бытия различных социальных систем (цивилизаций, государств, общественных и религиозных организаций, транснациональных корпораций и др.), характеризующихся крайней степенью неустойчивости состояния, неадекватностью в оценке обстановки и друг друга, разновекторной направленностью развития без учета взаимных интересов» [4, С. 14].

Структурно стратегическая нестабильность включает в себя субъекты, объекты, уровни, средства, технологии и регионы стратегической нестабильности. К субъектам стратегической нестабильности современные исследователи относят: а) транснациональные корпорации, компании и банки, осуществляющие хищническую финансово-экономическую деятельность; б) наиболее развитые государства мира, стремящиеся закрепить, развить и удержать собственное доминирование в мире в качестве супердержав; в) некоторые международные неправительственные и религиозные организации; г) политические и экономические элиты, неадекватно оценивающие свои возможности и потребности [4, С. 14].

По своему характеру стратегическая нестабильность выступает в качестве объективно-субъективного явления. Особенностью современного мирового развития является то, что оно все более приобретает субъективный технологический характер. Это связано с тем, что человек научными методами исследовал процессы хаоса и нестабильности и разработал их технологические аналоги. В этом отношении стратегическая нестабильность выступает в качестве технологии атомизации больших социальных структур (цивилизаций, регионов, государств, наций) со стороны доминирующих и господствующих в геополитическом и социально-экономическом отношении цивилизаций, государств и космополитических социальных групп, ориентированных на установление собственного геополитического и социального превосходства и стремящихся навязать миру свою модель глобализации как формат устроения мира в интересах только этих социальных субъектов [4].

Выделяют следующие уровни-измерения современной стратегической нестабильности: антропологическое, социально-экономическое, геополитическое, экологическое, технологическое и др. [4]

Важнейшей составляющей современной стратегической нестабильности стала дестабилизация социально-психологической обстановки в отдельных странах и целых регионах планеты. Это связано с той ролью, которую сегодня играют соотношение, сознание и поведение больших социальных групп, выделяемых из общего социального контекста по различным основаниям (национальному, расовому, религиозному, культурноисторическому, идеологическому, профессиональному, возрастному и др.). Именно на противоречиях между большими социальными группами разжигаются войны и революции, меняются политические режимы и разрушаются государства. Это дает основание говорить о нали- 
чии социально-психологического измерения современной стратегической нестабильности.

В современном глобализирующемся мире такая ситуация несет угрозу всему человечеству. Очаги нестабильности могут расширятся с непредсказуемой скоростью и масштабом. Вместе с тем распространение хаоса носит экстерриториальный характер. Не всегда можно спрогнозировать, где и как «откликнется». Кризисы, разгоревшиеся в одной точке земного шара, не только распространяются на соседние страны и регионы, но и находят свое продолжение в других регионах планеты, отделенных от них океанами.

О технологичности и управляемости современной стратегической нестабильности говорит анализ развития политических кризисов двух последних десятилетий. Практика неконституционного захвата власти в ходе «розовой революции» в Грузии (2003 год), «оранжевой революции» на Украине (2004 - 2005 годы), киргизских событий 2005 года, событий «арабской весны» на Ближнем Востоке (2010 - 2011 годы) и, так называемого, «евромайдана» на Украине (2014 год) имеют признаки применения внешнеполитическими акторами технологий управляемой дестабилизации. В вышеприведенных примерах таковыми являются активное участие иностранных государств и международных общественных организаций во всесторонней поддержке политической оппозиции, наличие схожего сценария развития протестных движений в данных государствах, высокий уровень организационно-технического обеспечения проводимых протестных акций, обязательная смена внешнеполитического вектора развития данных государств после смены политического режима, другие признаки, ещё подлежащие выявлению, систематизации и теоретическому анализу.

В качестве более свежего примера можно привести поствыборные события в Белоруссии 2020 года, когда в ходе направленной дестабилизации политической ситуации в стране использовался целый комплекс инструментов негативного информационно-психологического воздействия на общественное сознание как в целях нанесения экономического урона, так и в целях захвата власти.

В попытках подорвать внутриполитическую ситуацию в той или иной стране используются различные средства доставки деструктивного информационного контента. Самыми популярными из них стали социальные сети, мессенджеры, видеохостинги. Так, в ходе массовых протестов в Белоруссии такой «торпедой» стал мессенджер Telegram, а уже в январе 2021 года в России в ходе протестов сторонников А. Навального для мобилизации и координации протестующих использовалось приложение Tik Tok. Главное условие минимизация возможности контроля со стороны атакуемого государства.
Ранее в других странах и регионах планеты широко применялись Facebook, Twitter, YouTube. На современные технологии управления нестабильностью большое влияние оказывает технический прогресс, в частности, так называемая «цифровая революция» и связанная с ней глобальная информатизация. К примеру, использование интернета как канала протестной коммуникации сильно девальвировала значение уличных практик и роль площадных ораторов. Сегодня не улица генерирует лозунги протеста, она лишь транслирует то, что до этого подчерпнула главным образом из интернета. Социальные сети, мессенджеры, блогосфера, онлайн-сообщества стали инкубаторами взращивания протестного потенциала и радикальных протестных движений, средой распространения радикальных идей и средством управления дестабилизацией. При этом сам принцип мобилизации, технологии организации протеста не поменялись, методы остались те же. Подобно тому как столетие назад условием успеха восстания было взятие почтамта, газет, телеграфа, в наши дни все начинается с современных информационных ресурсов. Новые каналы коммуникаций дали непревзойденные преимущества тем, кто ими владеет.

Показателен пример из событий «арабской весны», после которой речь пошла о twitter- и facebookреволюциях. Ваэля Гонима, IT-инженера, директора по маркетингу компании «Google» на Ближнем Востоке и в Северной Африке, весь мир узнал в 2011 году, когда журнал Time поставил его на первую строчку самых влиятельных людей на планете. Летом 2010 года им была создана страница в Facebook, которую в первый день посетило чуть более десяти человек. Всего шесть месяцев спустя эта страница от имени трехсот пятидесяти тысяч подписчиков призвала к восстанию. 25 января 2011 г. восстание началось, 11 февраля 2011 г. власть Х. Мубарака была свергнута. Накануне восстания через различные сетевые форумы, политические веб-сайты, страницы Facebook и аккаунты Twitter распространился документ «Всё, что вам нужно знать про Jan25». Он включал в себя следующие разделы: 1. Кто мы? 2. Зачем протестовать? 3. Отчего Jan25? 4. Каковы наши требования? 5. Время и место протестов. 6. Основные положения. 7. Общие лозунги для скандирования» [10, С. 203-208].

За последние два десятилетия накоплен богатейший методический репертуар осуществления негативного информационно-психологического воздействия и набор форм представления деструктивного информационного контента. В частности, излюбленной и в тоже время эффективной, с точки зрения силы манипулятивного воздействия на общественное мнение, формой представления деструктивного информационного контента стали псевдожурналистские расследования.

С помощью технологий управляемой дестабилизации целенаправленно ведутся дезинформационные 
кампании против руководства стран-объектов агрессии, органов государственной власти, традиционных духовных ценностей общества. Все это быстро или постепенно «в раскачку» позволяет привести общественное сознание в нестабильное кризисное состояние. В свою очередь, кризисное сознание влечет за собой кризисное поведение общественных масс, которое при достижении определенных масштабов способно спровоцировать общенациональный кризис.

Вместе с тем негативное информационно-психологическое воздействие является только одним из технологических направлений управляемой дестабилизации.

После Второй Мировой войны, достигнув военно-силового паритета, СССР, США и образованные ими военно-политические блоки стали искать способы достижения внешнеполитических целей новыми средствами.

В 1948 году Советом национальной безопасности США принимается директива NSC 10/2, намечающая политику ЦРУ в плане подготовки и проведения широкого спектра «тайных операций».

«Под термином «тайные операции», употребляющимся в этой директиве, следует иметь в виду все виды деятельности (за исключением оговоренных ниже), которые проводятся или спонсируются правительством против враждебных иностранных государств или групп, или в поддержку дружественных иностранных государств или групп. Однако эта деятельность планируется и проводится так, чтобы ответственность за них американского правительства была не очевидна, а в случае её разоблачения правительство США может правдоподобно отрицать до конца всю ответственность за нее.

В частности, такие операции должны включать: пропаганду; экономическую войну; превентивные прямые действия, включая саботаж, противодействие саботажу, разрушения и эвакуацию; подрывную работу против иностранных государств, включая помощь подпольному движению сопротивления, партизанам и эмигрантским группам освобождения, поддержку антикоммунистических групп в странах свободного мира, находящихся под угрозой. В число таких действий не входит вооруженный конфликт с участием регулярных вооруженных сил, шпионаж и контршпионаж, прикрытие и обман в интересах ведения военных операций» [13].

Другой документ Совета национальной безопасности США этого же периода (директива 1948 года NSC 20/4) предписывал использовать «потенциал психологической войны и подрывной деятельности в советской сфере влияния, затем чтобы СССР столкнулся с усилением недовольства и подпольной оппозиции на территории, находящейся под советским контролем», а также «стимулировать развитие у народов России взглядов, которые могут способствовать изменению нынешнего советского поведения и возрождению национальной жизни этнических групп, их решимости добиваться и поддерживать национальную независимость»[14].

К противоборству подобного типа, не связанным с прямой вооруженной агрессией, применялся термин «политическая война» [14].

В последующие десятилетия формировались концепции войн нового типа и непрямой агрессии, которые и после распада СССР и нарушения послевоенного биполярного миропорядка получили дальнейшее широкое распространение. Из известных - это такие теоретические разработки как «технологии ненасильственных действий» Дж. Шарпа, концепция «сетецентрической войны» А. Себровски и Дж. Гарска, стратегия «мягкой силы» Дж. Ная, так называемая теория «управляемого хаоса» C. Манна, «теория пяти колец» Дж. Уордена, «DIME-войны» Ф. Бридлава (DIME - англ. абривиатура: дипломатия, информация, вооружённые силы, экономика) и «DIMETоперации» Д. Дептулы [11].

Предложенные такими авторами, как 3. Бжезинский, Г. Киссинджер, Дж. Най, С. Хантингтон, Дж. Шарп, теоретические концепции используются при реализации внешнеполитических стратегий США по отношению к России и постсоветскому пространству. Так, работа Дж. Шарпа «От диктатуры к демократии. Стратегия и практика освобождения» $[12$, С. 3] стала своеобразной «инструкцией» по организации цветных революций. Автором представлен перечень из 198 пунктов, подробно раскрывающих стратегию, которую необходимо применять при борьбе с неугодной государственной властью.

В работах зарубежных авторов, на исследованиях которых базировалась внешнеполитическая стратегия США в последней трети XX - начале XXI века представлено идеологическое обоснование смены политических режимов, которые не отвечают геополитическим интересам США.

Таким образом, хаотизация глобальных социальнополитических, финансово-экономических, культурно-мировоззренческих, информационно-коммуникационных и военно-стратегических процессов остро актуализирует проблему стратегической нестабильности как многомерного социального явления современности.

Сегодня становится все более очевидным то обстоятельство, что стратегическая нестабильность как форма бытия, функционирования и взаимодействия больших социальных систем, будучи исследованной человечеством на частнонаучном и междисциплинарном уровнях, подвергается управляющему воздействию, технологизируется и используется для достижения военных целей различными субъектами мировой политики без прямого открытого вооруженного противоборства, став 
способом управления глобальными процессами современности и достижения мирового господства. В связи с чем выработка эффективных и научно обоснованных мер противодействия технологиям управляемой дестабилизации становится залогом успешной организации национальной обороны и обеспечения национальной безопасности России.

Стратегией национальной безопасности Российской Федерации к основным угрозам государственной и общественной безопасности отнесена «деятельность радикальных общественных объединений и группировок, использующих националистическую и религиозно-экстремистскую идеологию, иностранных и международных неправительственных организаций, финансовых и экономических структур, а также частных лиц, направленная на нарушение единства и территориальной целостности Российской Федерации, дестабилизацию внутриполитической и социальной ситуации в стране, включая инспирирование «цветных революций» [8].

Понимая современную стратегическую нестабильность, как сложное социальное явление, определяющее форму правления отдельных государств, социально-политическое и экономическое устройство современных общественных систем, интенсивность и направленность их трансформации, систему международных отношений и геополитическую картину мира в целом, развивающееся по объективным законам, закономерностям и принципами социального бытия, нельзя отрицать, что человечество исследовало ее до технологической степени управляемости и военного применения. Вместе с тем применение технологий стратегической дестабилизации, как способа военного противоборства, как продолжение политики иными средствами, как попытку конструировать будущее человечества, представляется крайне опасным для всего мирового сообщества и существования человеческой цивилизации. Это утверждение представляется таким же справедливым, как было бы справедливым аналогичное утверждение, относительно применения современных технологий ядерного вооружения.

В этом ключе крайне актуально и остро звучало известное выступление Президента России В.В. Путина: «Экспорт социальных экспериментов, попытки подстегнуть перемены в тех или иных странах, исходя из своих идеологических установок, часто приводили к трагическим последствиям, приводили не к прогрессу, а к деградации. Однако, похоже, никто не учится на чужих ошибках, а только повторяет их. И экспорт теперь уже так называемых «демократических» революций продолжается... Но что получилось на деле? Агрессивное внешнее вмешательство привело к тому, что вместо реформ государственные институты, да и сам уклад жизни были просто бесцеремонно разрушены. Вместо торжества демократии и прогресса - насилие, нищета, социальная катастрофа, а права человека, включая и право на жизнь, ни во что не ставятся. Так и хочется спросить тех, кто создал такую ситуацию: «Вы хоть понимаете теперь, что вы натворили?» [2].

\section{ЛИТЕРАТУРА}

1. Большая российская энциклопедия / URL: https://bigenc.ru/military_science/text (дата обращения: 04.03.2020 г.).

2. Из выступления Президента Российской Федерации В.В. Путина на 70-й сессии Генеральной Ассамблеи 00Н.

3. Лебон Г. Психология масс. С предисловием Н. Старикова. СПб.: Питер, 2015. 244 с.

4. Мандрыка С.М. Государственная безопасность в условиях современной стратегической нестабильности (социально-философский анализ): Автореф. дис. кан-та филос. наук. М. 2008. 25 с.

5. Панарин А.С. Стратегическая нестабильность в XXI веке. М., 2003. С. 5.

6. Ромашкина Н.П. Стратегическая стабильность в эпоху информационно-коммуникационных технологий // URL: https://russiancouncil.ru/analiytics-andcomments (дата обращения: 04.03.2020 г.).

7. Сорокин П.А. Социология революции. М.: Российская политическая энциклопедия (РОССПЭН), 2010. 552 с.

8. Указ Президента РФ от 31 декабря 2015 г. № 683 «0 Стратегии национальной безопасности Российской Федерации» // URL: http://base.garant. ru/71296054/\#friends (дата обращения: 26.02.2018).

9. Шульц Э.Э. Причины революций: голова или кошелек? // Историческая психология и социология истории. Том 7, номер 1/2014 // URL: http://www. socionauki.ru/journal/articles/244526/ (дата обращения: 12.09 .2018 г.).

10. Гоним В. Революция 2.0: документальный роман / пер. с англ. Т. Даниловой. СПб.: Издательская группа «Лениздат», «Команда А», 2012. С. $203-208$.

11. Овчинский В., Ларина Е. Холодная война 2.0 // Изборский клуб. Русские стратегии. Выпуск 9 (11). М., 2014.

12. Шарп Д. От диктатуры к демократии: Стратегия и тактика освобождения. М.: Новое издательство, 2012, 84 с.

13. National Security Council Directive NSC 10/2 // Archives/Washington D. C. (États-Unis)/18 June 1948 // URL: http://www.voltairenet/org/article163480.html (дата обращения: 23.05.2021 г.).

14. National Security Council Directive NSC 20/4 // URL: http://history.state.gov/historicaldocuments/frus1948v01p2/d61 (дата 0бращения: 23.05.2021 г.). 